\title{
CORRIGENDUM
}

\section{Flavoring exposure in food manufacturing}

Brian D. Curwin, Jim A. Deddens and Lauralynn T. McKernan

Journal of Exposure Science and Environmental Epidemiology (2015) 25, 121; doi:10.1038/jes.2014.80

Correction to: Journal of Exposure Science and Environmental Epidemiology (2014). doi:10.1038/jes.2014.52; published online 23 July 2014

The following funding source for this article was unintentionally omitted: "This study was supported in part by an interagency agreement between the National Institute for Occupational Safety and Health (NIOSH) and the National Institute of Environmental Health Sciences (NIEHS) (Y1-ES-9018-02) as a collaborative National Toxicology Program research activity." The authors regret the error. 